\title{
About loading of autotransformers in main electrical grids and conclusions for designing
}

\author{
Nikita Vasilenko ${ }^{1}$, Vladislav Plotnikov ${ }^{1}$, and Andrey Shuntov ${ }^{1 *}$ \\ ${ }^{1}$ National research university "MPEI",Institute of Electrical Power Engineering, 14 Krasnokazarmennaya St, Moscow, Russia
}

\begin{abstract}
The justification issues and the capacity selection of autotransformers in the main electrical grids, which require the accounting of the operation regimes of power units for the future of 10 or more years are considered. Appropriate methodological provisions for justification and choice in terms of generalized load schedules, load capacity of transformer equipment, as well as assessing the reliability of electrical installations in the design and development of the energy systems are proposed.
\end{abstract}

\section{Introduction}

Autotransformers rated capacity $\left(S_{\text {rated }}\right)$ is selected with taking into account of kind of load characteristic, permissible normal cyclic loading and emergency loading. The first could have place systematically under uneven daily load-graph, the second - in emergency when maintenance of consumer power supply is needed regardless of autotransformers overloading.

Starting point of determination of load capability of autotransformer is its daily load-graph converted into equivalent two-stage load graph. Methods of conversion and definition of load capability are specified in Russian literature [1-2 etc] and international literature [3]; they are well known and are not considered in this paper. Accepted practice of justification and selection autotransformer capacity does not bring methodical problems in the design of power-supply system of particular consumers. There is understanding of normal load graph shape for them.

However, it is alternately for electrical installations in main electrical grids. Particularly for large system substations with autotransformers $220-750 \mathrm{kV}$ related to Unified National Power Grid. Selection of their capacity is performed on 10 and more year's long term in electrical energy system development scheme and main electrical grids development scheme, i. e. under conditions of material uncertainties. In this case, substation load graphs are defined not by particular consumers, but interconnection operational states. On practice project engineer operate not with load graphs, but with predicted values of main electrical grids power flows in the period of winter and summer maximal load.

Moreover, scope of regulation [1] does not apply to lion's share of autotransformers installed in main electrical grids - installations $220 \mathrm{kV}$ and above with capacity from 125 to 800 MVA with OF cooling system. Therefore, project engineers do not have methodical base for making decision in the problem domain.

Finally, consideration of virtually any possible rated condition in electrical energy system becomes a regular practice.

\section{Loading of autotransformers}

Modern software applications that calculate steadystate regimes allow calculating and ranging fast thousands of electrical energy system conditions.

Exhaustive search of any possible regimes in electrical energy system not only with n-1 principle (failure of one network element), but also with failure of two concurrent network elements (n-2 principle) becomes compulsory in designing substations. Thus, for substations - failure of any overhead power transmission line (OHL) $110 \mathrm{kV}$ and above in electrical energy system under planned outage of AT in considering electrical installation. A number of regimes can come to hundreds. Regime with AT loading higher than in regime with N-1 principle always can be found. It is harder regime, but half-proven for capacity selection.

As a result of all listed factors of main electrical grids a low load of expensive transformer installations reveals itself. By authors calculations in the real network map $110 \mathrm{kV}$ and above in the period of maximum load of 2015 year in n-1 regime about $90 \%$ of AT are not loaded higher than their rate capacity. In addition, their average loading in considering regime is equal about $60 \% S_{\text {rated }}$ and it is independent of year of commissioning of equipment.

As mentioned before, AT loading in main electrical grids is determined by interconnection operational states: balance power flows, flows connected with realization of interconnection effect and system reliability, high-water period passage conditions, etc.

Values of characteristic equivalent two-stage load graphs of substations $220-500 \mathrm{kV}$ from different regions of the country are given in the Table 1 . There were processed real daily check measurements of check measurement days in 2015 year for more than 500 substations according with their voltage type. Defined:

- $\mathrm{f}_{\max }$ factor, calculated as the winter peak load $\left(S_{\max (\mathrm{w})}\right)$ divided by the summer peak load $\left(S_{\max (\mathrm{s})}\right)$;

\footnotetext{
Corresponding author: sh280859@gmail.com
} 
- load factor $f_{\text {load }}$ (the average load divided by the peak load);

- load curve irregularity factor $f_{\text {irreg }}$ (the minimum load divided by the peak load).

The defined average value of $f_{\max }=1,2$. However, the summer peak of about $30 \%$ substations is higher than the winter peak, i.e. $\mathrm{f}_{\max }<1,0$. These substations exist in all regions. It is harder design condition, be- cause rated AT capacity conform to ambient temperature of $20^{\circ} \mathrm{C}$, i.e. permissible loading is decreasing while growth of temperature and conversely.

Average country values are $f_{\text {load }}=0,825$ and $f_{\text {irreg }}=0,627$. Therefore, average pre-load $K_{1}$ of equivalent two-stage load graph is in comparably narrow range $0,627<K_{1}<0,825$ (arithmetical averages were taken nextly).

Table 1. Characteristics of Equivalent two-stage load graph

\begin{tabular}{|c|c|c|c|c|c|c|}
\hline Prevalent type of load & $f_{\text {irreg, }}$ pu. & $f_{\text {load }}$, pu. & $K_{1}$, pu. & $K_{2}$, pu. & $h, \mathrm{~h}$ & $T_{\max }, \mathrm{h}$ \\
\hline The first group - industrial (regions of Siberia) & 0,920 & 0,834 & 0,877 & 1,0 & 8,4 & 7547 \\
\hline $\begin{array}{c}\text { The second group - zone of large industrial } \\
\text { centers and cities (regions of Ural) }\end{array}$ & 0,844 & 0,659 & 0,751 & 1,0 & 9,0 & 6719 \\
\hline The third group - mixed (Central regions) & 0,820 & 0,611 & 0,716 & 1,0 & 8,8 & 6413 \\
\hline $\begin{array}{c}\text { The fourth group - mixed with developed agri- } \\
\text { cultural industry (South regions) }\end{array}$ & 0,762 & 0,497 & 0,630 & 1,0 & 8,6 & 6128 \\
\hline Country average & 0,825 & 0,627 & 0,726 & 1,0 & 8,7 & 6685 \\
\hline
\end{tabular}

Characteristics of daily load graph structured in the Table 1 by four formal groups from the perspective of type of substation load with subsequent calculation of average values. The first group - industrial, it is representative of oil production regions enhanced by high share of hydro power plants in the mix of generating plants in some cases. The second group - zone of large industrial centers and cities. The third group - mixed type of load with measurable percent of domestic consumer and service sector demand. And the fourth group - the same as the third group, but with developed agricultural industry.

Conversion of daily load graph into equivalent twostage load graph was realized the following manner. For $f_{\text {load }}$ and $f_{\text {irreg }}$ from the Table 1 when $\mathrm{K} 2=1$ there was defined pre-load $\mathrm{K} 1=\left(f_{\text {load }}+f_{\text {irreg }}\right) / 2$. We call duration of $\mathrm{K} 1$, as $\mathrm{x}$. Therefore, duration of $\mathrm{K} 2$ is $24-\mathrm{x}$ и 24 firreg $=K 1 \mathrm{x}+\mathrm{K} 2(24-\mathrm{x})$. Thus for country average values (Table 1) we have: $24 \cdot 0,825=0,726 x+1,0(24-x)$. From which $\mathrm{x} \approx 15,3 \mathrm{~h}$., and the duration of potential overload $\mathrm{K} 2 \mathrm{~h}=8,7 \mathrm{~h}$.

It will be seen from the Table 1 the equivalent load graphs could be differ in values of $\mathrm{K} 1$. They're varying in in the range of 0,63 to 0,88 with almost constant duration of overload $\mathrm{h} \approx 8-9$ hours.
In the basis of Russian and international methods of definition of loading capacity of (auto)transformers there're thermal model of ageing of their insulation, top-oil and hot-spot temperature limitations and number of other boundary conditions $[1,2]$. From the perspective of insulation ageing the known $6^{\circ} \mathrm{C}$ principle is used. However, permitted temperatures are different in $[1,2]$ (Table 2). The international standards are more sparing. Thus, maxi-mum permissible winding hot-spot temperature from [1] $-160^{\circ} \mathrm{C}$, while in [2] $-140^{\circ} \mathrm{C}$ (Table 2).

AT loading examples are given in Figure 1: solid lines - normal cyclic loading, dashed lines - emergency loading. Curves in Figure 1 are given for equivalent ambient temperature of $+20^{\circ} \mathrm{C}$, curves in Figure 1 , a are given for equivalent ambient temperature of $-10^{\circ} \mathrm{C}$ and for $+20^{\circ} \mathrm{C}$ in Figure 1,b. It is typical for Moscow region for winter and summer periods thoroughly. Calculations were settled by the procedure [2]. Normal cyclic loadings were calculated with daily loss of life is less than 1. Numbers with daggers in Figure 1 - duration (h) of overloading K2. The current limitation from Table 2 , which is $K 2 \leq 1,3$, is disregarded in Figure 1 .

Table 2. Maximum permissible characteristics of autotransformers

\begin{tabular}{|l|c|c|c|}
\hline \multicolumn{1}{|c|}{ Characteristic } & \multicolumn{3}{c|}{ (auto)transformers capacity, MV A } \\
\cline { 2 - 4 } & to 2,5 & from 2,5 to 100 & above 100 \\
\hline Normal cyclic load: & & & \\
Current, pu. & $1,5 / 1,5 / 1,5$ & $1,5 / 1,5 / 1,5$ & $* * / 1,3 / 1,3$ \\
Winding hot-spot temperature, ${ }^{\circ} \mathrm{C}$ & $140 / 140 / 120$ & $140 / 140 / 120$ & $* * / 120 / 120$ \\
Top-oil temperature, ${ }^{\circ} \mathrm{C}$ & $95 / 105 / 105$ & $95 / 105 / 105$ & $* * / 105 / 105$ \\
Long-time emergency loading: & & & \\
Current, pu. & $2,0 / 1,8 / 1,8$ & $2,0 / 1,5 / 1,5$ & $* * / 1,3 / 1,3$ \\
Winding hot-spot temperature, ${ }^{\circ} \mathrm{C}$ & $160 / 150 / 140$ & $160 *(140 *) / 140 / 140$ & $* * / 130 / 140$ \\
Top-oil temperature, ${ }^{\circ} \mathrm{C}$ & $115 / 115 / 115$ & $115 / 115 / 115$ & $* * / 115 / 115$ \\
\hline
\end{tabular}

Note: the first number - from GOST 14209 - 85; the second - from IEC 354 - 91, the third - from IEC 60076 - 7:2005; * the first number for transformers up to $110 \mathrm{kV}$, the second - above $110 \mathrm{kV} * *$ - not rated

From Figure 1 follows: AT loading for the real values $K_{1} \approx 0,6-0,9$ and $h \approx 8-9$ hours (Table 1 ) is almost constant. Thus, for equivalent temperature of $-10^{\circ} \mathrm{C}$ the normal cyclic loading $K_{2} \approx 1,2$ and emergency loading 1,5 (Figure 1,a). For normal cyclic loading it's explained by the limitation of defined (as above) daily loss of life while the winding hot-spot temperature is below permitted value $-120^{\circ} \mathrm{C}$ and for emergency loading - by the winding hot-spot temperature is below $140^{\circ} \mathrm{C}$. 
The regularity revealed in permitted loads of AT is essential in a context of uncertainty of initial data for making decisions on the period 10 years or above. From Figure 1 also follows that emergency loading is

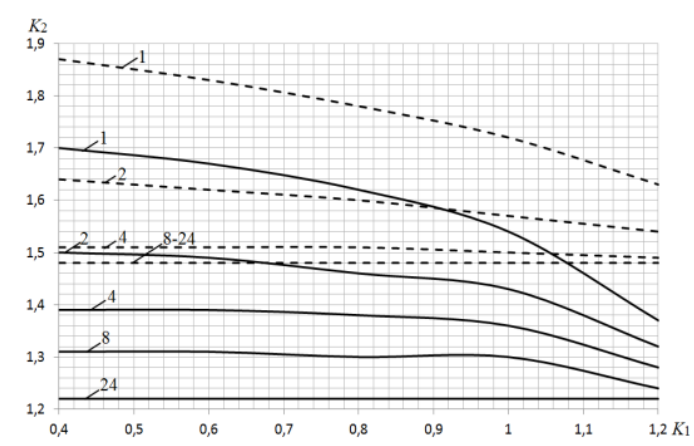

Fig. 1.a Loading of AT which rating over $100 \mathrm{MV} \cdot \mathrm{A}$ with OF cooling system for $-10^{\circ} \mathrm{C}$.

Loading is divided proportional between them if possible in steady state regime. That's why most of the time they're underloaded and mid-annual duration of power system maintenance regime and postfault regime, as a rule, doesn't exceed 1/10 part of a year. In this case, normal cyclic loads can be limited not by daily loss of life, but the maximum permissible winding hot-spot temperature $\left(120^{\circ} \mathrm{C}-\right.$ Table 2$)$.

For this controlling case permissible cyclic loading of AT which rating over $100 \mathrm{MV} \cdot \mathrm{A}$ with OF cooling system is given in Table 3 for equivalent ambient temperature $+20^{\circ} \mathrm{C}$ (numerator) and corresponding daily loss of life (denominator).

The comparison of data from Table 1 and Figure 1,b shows: with removing constraints from daily loss of life under other factors being equal the permissible loading $K_{2}$ is growing from 1,0 to 1,16 . In this case daily loss of life for $\mathrm{h}=8$ hours doesn't exceeded 3,98. Thus, in calendar day insulation is really «outmoded» on 3,98 days. For example, if annual average outage doesn't exceed, assume, a month then insulation will be outmoded on $30 \cdot 3,98=120$ days for this period.

In a steady state regime when two AT are in service and the loading of each is $(1,16 / 2) S_{\text {rated }}$, the daily loss of life is less than 0,01 (the winding hot-spot temperature is $57^{\circ} \mathrm{C}$ ), so it can be neglected. This state is common to temperatures up to $80^{\circ} \mathrm{C}$. Thus, determination of permissible cyclic loading based on winding hot- on $0,2-0,3$ higher than normal cyclic loading with other factors being equal.

The above-accepted limitation for daily loss of life can be reduced. Usually there are two autotransformers installed on substations.

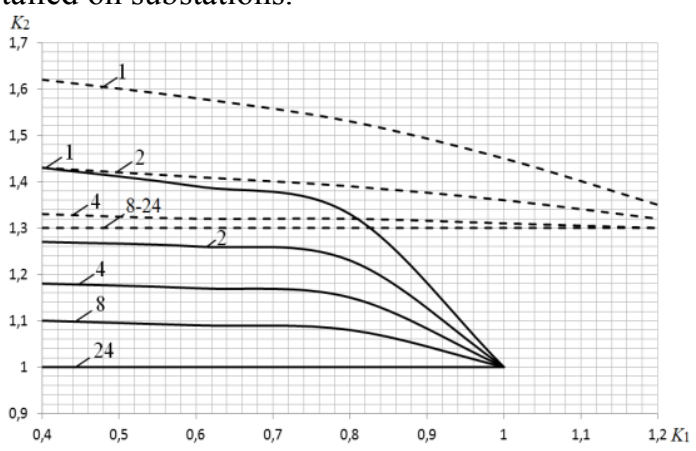

Fig. 1.b Loading of AT which rating over $100 \mathrm{MV} \cdot \mathrm{A}$ with OF cooling system for $+20^{\circ} \mathrm{C}$.

spot temperature is proven design condition for increasing of AT loading.

As it was mentioned above, $n-1$ and $n-2$ regimes are taken into account for justification and selection autotransformer capacity. The last also is harder designing condition. It is interesting to estimate its real severity.

There were calculated AT loadings $S_{n-1}$ and $S_{n-2}$ on 73 functioning two-transformer substations 220$500 \mathrm{kV}$ in $n-1$ and $n-2$ in all regions of the country for peak loading scheme of 2015 year (Table 4). N-1 regimes were modeled with failure of one AT on a substation. In $\mathrm{n}-2$ regimes all OHL $110 \mathrm{kV}$ and above in a region were orderly and sequential failure in addition to $n-1$ regimes. For one particular substation, the number of design regimes was in the range of 100 to 400 . Regimes were ranked depending on $S_{n-2} / S_{n-1}$ ratio (Table 4). From Table 4 follows:

- From 16073 design $n-2$ regimes about 30\% (4919 regimes) lead to excess $S_{n-2}>S_{n-1}$;

- From chosen 4919 regimes 4718 design conditions $(95,9 \%)$ lead to excess of autotransformer loading less than 0,1 in comparison with the same in $n-1$ regime and $4718+115=4833(98,3 \%)-$ less than 0,2 ;

- The number of regimes, where $S_{n-2} / S_{n-1}>1,1$, decreases rapidly with increasing of power surge;

- Between 16073 design regimes there was found one extreme went with $S_{n-2} / S_{n-1}=1,81$.

Table 3. Cyclic loading and daily insulation loss of life for winding hot-spot temperature of $120^{\circ} \mathrm{C}$

\begin{tabular}{|c|c|c|c|c|c|}
\hline \multirow{2}{*}{ Overload duration, $h$} & \multicolumn{5}{|c|}{ Permissible overload $K_{2}$ for $K_{1}=0,4-1,2$} \\
\cline { 2 - 6 } & 0,4 & 0,6 & 0,8 & 1,0 & 1,2 \\
\hline \multirow{2}{*}{1,0} & $\frac{1,43}{0,60}$ & $\frac{1,39}{0,64}$ & $\frac{1,33}{0,77}$ & $\frac{1,25}{1,89}$ & - \\
\hline 2,0 & $\frac{1,27}{0,61}$ & $\frac{1,26}{0,67}$ & $\frac{1,23}{0,78}$ & $\frac{1,20}{1,90}$ & - \\
\hline \multirow{2}{*}{4,0} & $\frac{1,19}{1,05}$ & $\frac{1,18}{1,06}$ & $\frac{1,18}{1,35}$ & $\frac{1,17}{2,47}$ & - \\
\hline \multirow{2}{*}{8,0} & $\frac{1,16}{2,44}$ & $\frac{1,16}{2,57}$ & $\frac{1,16}{2,85}$ & $\frac{1,16}{3,98}$ & - \\
\hline \multirow{2}{*}{24,0} & $\frac{1,16}{11,10}$ & $\frac{1,16}{11,20}$ & $\frac{1,16}{11,46}$ & $\frac{1,16}{11,77}$ & - \\
\hline
\end{tabular}


As was shown before, emergency loading is on $0,2-$ 0,3 higher than normal cyclic loading with other factors being equal. Therefore, if AT capacity is selected according to $n-1$ regime, then while verify it in $n-2$ regime we can exclude $98,3 \%$ design conditions (Table 4) from consideration, $S_{n-2} / S_{n-1}<1,2$. Next, we will do reliability evaluation of $n-1$ regimes for the real example.

In detailed analysis of all variety regimes, (Table 5) authors could not found even one for reliability measurement. As a fact capacities of AT in main electrical grids in the most cases are exceed power flows through AT not only in n-1 regime, but also in $n-2$ regime. In other words, rated capacities of given installations due to various reasons turn out to be such uprated, that it's impossible to estimate real limitations for doing reliability evaluation. For example, let's take into consideration the substation № 6 from Table 5 with almost twice power surge in $n-2$ regime $\left(S_{n-2} / S_{n-1}=1,81\right)$. It has two installed groups of single-phase autotransformers $500 / 220 \mathrm{kV}$ with capacity of $3 \cdot 167 \mathrm{MV} \cdot \mathrm{A}$ each group. In a steady state regime the peak loading of AT is $0,16 S_{\text {rated }}$, in the n- 1 regime is $0,22 S_{\text {rated }}$, and in the n-2 regime is $0,39 S_{\text {rated. }}$ That is why regime reliability factor is analyzed from a perspective of hypothetical reasonability of decreasing of installed AT loading.

In this context the substation № 5, which is located at the interface of Ural and West-Siberian regions, is demonstrative example.
It has two installed AT 220/110 kV with $S_{\text {rated }}=250 \mathrm{MV} \cdot \mathrm{A}$. Real characteristics of equivalent two-stage load graph of the substation - $K_{1}=0,726$, $h=9,6 \mathrm{~h} ; S_{\max (\mathrm{w})} / S_{\max (\mathrm{s})}=1,32 ; T_{\max }=6522 \mathrm{~h}$. Maximal power flow in $\mathrm{n}-2$ regime in the period of winter peak loading is $200 \mathrm{MV} \cdot \mathrm{A}\left(\max \left(S_{n-2} / S_{\text {ном }}\right)=0,8\right)$ and in $\mathrm{n}-1$ regime is $145 \mathrm{MV} \cdot \mathrm{A}\left(S_{n-2} / S_{n-1}=1,38\right)$. It is caused by emergency failure of $\mathrm{OHL} 500 \mathrm{kV}$ with length $l=113 \mathrm{~km}$. The second estimated event - failure of another OHL $500 \mathrm{kV}$ with length $l=60 \mathrm{~km}\left(S_{n-2} / S_{n-}\right.$ $\left.{ }_{1}=1,32\right)$. The third - failure of OHL $110 \mathrm{kV}$ with length $l=101 \mathrm{~km}\left(S_{n-2} / S_{n-1}=1,21\right)$. Then a logical question appears: could we use autotransformers with rated capacity of $125 \mathrm{MV} \cdot \mathrm{A}$ instead of $250 \mathrm{MV} \cdot \mathrm{A}$ on the substation?

AT loading in n-1 regime will be $145 / 125=1,16$. Even for $+20^{\circ} \mathrm{C}$ such cyclic loading is permitted (Table 3 ). We can consider that emergency loading in $n-2$ regime could be 0,2 higher than permitted cyclic loading; total $K_{2}=1,16+0,2=1,36$. Estimated event is harder with taking into account of current limitation $125 \cdot 1,3 \approx 163 \mathrm{MV} \cdot \mathrm{A}$ according with [2]. Therefore, the loading of substation in $n-2$ regime should be limited to 200-163=37 MV·A $(\triangle P \approx 37 \mathrm{MW})$. Limitations for the second and third estimated events are 28 and $12 \mathrm{MW}$. Other $n-2$ regimes from ranges of $0-10$ and $10-20 \%$ from Table 4 are neglected, because they do not lead to exceeding of permissible emergency loading of AT.

Table 4. AT loading on substations in $n-2$ regime

\begin{tabular}{|c|c|c|c|c|c|c|c|c|c|c|c|c|}
\hline \multirow{2}{*}{ № } & \multirow{2}{*}{$\begin{array}{l}\text { Amount } \\
\text { of re- } \\
\text { gimes, ea }\end{array}$} & \multicolumn{10}{|c|}{ Among them regimes, ea, leading to $S_{n-2} / S_{n-1}>1$ within the ranges, $\%$} & \multirow{2}{*}{$\begin{array}{l}\quad \max \\
\left(S_{n-2} / S_{\text {rated }}\right) \\
\mathrm{pu}\end{array}$} \\
\hline & & $0-10$ & $10-20$ & $20-30$ & $30-40$ & $40-50$ & $50-60$ & $60-70$ & $70-80$ & $80-90$ & $0-90$ & \\
\hline \multicolumn{13}{|c|}{$500 \mathrm{kV}$} \\
\hline 1 & 113 & 50 & 0 & 0 & 0 & 0 & 0 & 0 & 0 & 0 & 50 & 0,79 \\
\hline 2 & 140 & 58 & 1 & 0 & 0 & 1 & 0 & 0 & 0 & 0 & 60 & 0,70 \\
\hline 3 & 352 & 108 & 4 & 0 & 0 & 0 & 0 & 0 & 0 & 0 & 112 & 0,79 \\
\hline 4 & 176 & 81 & 2 & 3 & 1 & 0 & 0 & 0 & 0 & 0 & 87 & 0,67 \\
\hline 5 & 352 & 119 & 5 & 2 & 1 & 1 & 0 & 0 & 0 & 0 & 128 & 0,35 \\
\hline 6 & 352 & 23 & 2 & 0 & 0 & 1 & 0 & 0 & 0 & 1 & 27 & 0,39 \\
\hline 7 & 390 & 304 & 4 & 2 & 0 & 0 & 0 & 0 & 0 & 0 & 310 & 0,63 \\
\hline 8 & 390 & 138 & 0 & 0 & 1 & 2 & 0 & 0 & 0 & 0 & 141 & 1,11 \\
\hline$\ldots$ & $\ldots$ & $\ldots$ & $\ldots$ & $\ldots$ & $\ldots$ & $\ldots$ & $\ldots$ & $\ldots$ & $\ldots$ & $\ldots$ & $\ldots$ & \\
\hline 27 & 254 & 127 & 1 & 0 & 0 & 0 & 0 & 0 & 0 & 0 & 128 & 1,39 \\
\hline $1-27$ & 6733 & 2467 & 56 & 15 & 5 & 5 & 1 & 0 & 0 & 1 & 2550 & \\
\hline \multicolumn{13}{|c|}{$220 \mathrm{kV}$} \\
\hline 28 & 132 & 32 & 0 & 0 & 0 & 0 & 0 & 0 & 0 & 0 & 32 & 0,56 \\
\hline 29 & 113 & 48 & 2 & 4 & 5 & 0 & 1 & 0 & 0 & 0 & 60 & 0,70 \\
\hline 30 & 140 & 54 & 4 & 1 & 0 & 0 & 1 & 0 & 0 & 0 & 60 & 0,31 \\
\hline 31 & 254 & 115 & 1 & 0 & 0 & 0 & 0 & 0 & 0 & 0 & 116 & 1,12 \\
\hline 32 & 113 & 30 & 2 & 0 & 0 & 1 & 1 & 1 & 0 & 0 & 35 & 0,60 \\
\hline 33 & 390 & 46 & 0 & 0 & 0 & 0 & 0 & 0 & 0 & 0 & 46 & 0,86 \\
\hline 34 & 230 & 152 & 2 & 6 & 0 & 0 & 0 & 0 & 0 & 0 & 160 & 0,50 \\
\hline 35 & 230 & 73 & 2 & 1 & 2 & 0 & 0 & 0 & 0 & 0 & 78 & 0,80 \\
\hline$\ldots$ & $\ldots$ & $\ldots$ & $\ldots$ & $\ldots$ & $\ldots$ & $\ldots$ & $\ldots$ & $\ldots$ & $\ldots$ & $\ldots$ & $\ldots$ & $\ldots$ \\
\hline 73 & 230 & 40 & 0 & 0 & 1 & 0 & 1 & 0 & 0 & 0 & 42 & 0,62 \\
\hline $28-73$ & 9340 & 2251 & 59 & 35 & 14 & 3 & 6 & 1 & 0 & 0 & 2369 & \\
\hline \multicolumn{13}{|c|}{$220-500 \mathrm{kV}$} \\
\hline $1-73$ & 16073 & 4718 & 115 & 50 & 19 & 8 & 7 & 1 & 0 & 1 & 4919 & \\
\hline
\end{tabular}


Table 5. For $n-2$ regimes reliability estimation

\begin{tabular}{|c|c|c|c|}
\hline \multirow{2}{*}{ Index } & \multicolumn{3}{|c|}{ Estimated event } \\
\cline { 2 - 4 } & $l=113 \mathrm{~km}, \Delta P=37 \mathrm{MW}$ & $l=60 \mathrm{~km}, \Delta P=28 \mathrm{MW}$ & $9,3 \cdot 10^{-3}$ \\
\hline$\Phi_{\Sigma}, 1 /$ year & $4,1 \cdot 10^{-3}$ & $2,3 \cdot 10^{-3}$ & 7,2 \\
\hline$m_{\mathrm{t}}$, hours & 9,8 & 9,9 & 108 \\
\hline $1 / \Phi_{\Gamma}$, year & 244 & 442 & $7,7 \cdot 10^{-6}$ \\
\hline$f_{\mathrm{of}}, \mathrm{pu}$ & $4,6 \cdot 10^{-6}$ & $2,6 \cdot 10^{-6}$ & 1,2 \\
\hline$\Delta W, \mathrm{MW} \cdot \mathrm{h}$ & 2,2 & 0,9 & \\
\hline \multicolumn{2}{|r|}{ Total $\Delta W=2,2+0,9+1,2 \approx 4,0 \mathrm{MW} \cdot \mathrm{h}$} \\
\hline
\end{tabular}

Reliability characteristics of n-2 regimes for considering substation are given in Table 5. Agreed notations in Table 5: $\omega_{\Sigma}-$ resulting fault rate; $m_{\mathrm{t}}-$ mean time to scheme repair; $f_{\text {of }}-$ scheme forced outage factor; $\Delta W$ - mathematical expectation of annual electricity sacrifice due to scheme unreliability. From Table 5 follows, that rate of occurrence of $n-2$ regimes is one time in $100-500$ years.

Economic impact evaluation due to schemes unreliability has always caused great uncertainty because of known reasons. Setting aside them, please note that in recent years results of the most large-scale research in the area of values of specific damage by electricity sacrifice were published in $[3,4]$. Thus, when selecting a scheme of main electrical grids aggregated data of specific damage is recommended at a level of 18$42 \mathrm{rub} . /(\mathrm{kW} \cdot \mathrm{h})$ at 2000 values. Therewith, weighted average value of specific damage in countries of Western Europe, the USA and Canada is 9,53 dol./(kW·h). For liquidation of power flows limitations in $n-2$ regimes it is possible to go towards a variant of increasing AT capacity from 125 to $200 \mathrm{MV} \cdot \mathrm{A}$.

Discounted costs estimation for considering variants is trivial. For maximum recommended value of specific damage $240 \mathrm{rub} . /(\mathrm{kW} \cdot \mathrm{h})$ the economic impact due to schemes unreliability for $\Delta W \approx 4,0 \mathrm{MW} \cdot \mathrm{h}$ is up by more than decade of expenses, connected with increasing AT capacity. The same for taking the value of specific damage of countries of Western Europe, the USA and Canada.

Then a logical question appears: when $n-2$ regimes should be taken into account for technical and economic assessment of optimum level of probability of electrical installation? In analyzed substation scheme, it will be necessary, If power limitation is up by more than decade, i.e. not 37 , but $370 \mathrm{MW}$, when $S_{n-2} / S_{n \text { - }}$
${ }_{1}=(170+370) / 145=3,7$. Taking into account of factual data from Table 4 such a regime is unlikely possible.

\section{Conclusion}

Therefore, for selection of AT capacity in main electrical grids of electrical energy system one may recommend the following rules:

1. AT capacity is selected based on maximum power flow in n-1 regime with failure of one of AT on a substation.

2. There should not be power flows limitations in n1 regime with taking into account a permissible cyclic loading of AT.

3. Cyclic loading is estimated based on nonexceedance of winding hot-spot temperature without AT insulation loss of life limitation.

4. Upon that, n-2 regimes are not considered, but they are considered for Emergency Control Automatics requirements definition.

\section{References}

1. State Standard 14209 - 85. General-purpose oilimmersed power transformers. Permissible loads. (Standartinform Publ., Moscow 2009)

2. B.N. Neklepaev Electric Part of Power Stations and Substations (Energoatomizdat 1986)

3. IEC 60076- 7 - 2005. Power transformers - Part 7: Loading guide for oil-immersed power transformers. (IEC, 2005)

4. V.A. Nepomnyaschiy Power market, 9, 36- 47. (2014) 